\title{
Cloning and Characterization of Pectate Lyases Expressed in the Esophageal Gland of the Pine Wood Nematode Bursaphelenchus xylophilus
}

\author{
Taisei Kikuchi, ${ }^{1}$ Hajime Shibuya, ${ }^{1}$ Takuya Aikawa, ${ }^{1}$ and John T. Jones ${ }^{2}$ \\ ${ }^{1}$ Forestry and Forest Products Research Institute, Tsukuba, Ibaraki 305-8687, Japan; ${ }^{2}$ Plant-Pathogen Interactions \\ Programme, Scottish Crop Research Institute, Invergowrie, Dundee, DD2 5DA, U.K.
}

Submitted 30 August 2005. Accepted 3 November 2005.

Two pectate lyase genes (Bx-pel-1 and Bx-pel-2) were cloned from the pine wood nematode, Bursaphelenchus $x y$ lophilus. The deduced amino acid sequences of these pectate lyases are most similar to polysaccharide lyase family 3 proteins. Recombinant BxPEL1 showed highest activity on polygalacturonic acid and lower activity on more highly methylated pectin. Recombinant BxPEL1 demonstrated full dependency on $\mathrm{Ca}^{2+}$ for activity and optimal activity at $55^{\circ} \mathrm{C}$ and $\mathrm{pH} 8$ to 10 like other pectate lyases of polysaccharide lyase family 3 . The protein sequences have predicted signal peptides at their $\mathrm{N}$-termini and the genes are expressed solely in the esophageal gland cells of the nematode, indicating that the pectate lyases could be secreted into plant tissues to help feeding and migration in the tree. This study suggests that pectate lyases are widely distributed in plant-parasitic nematodes and play an important role in plant-nematode interactions.

Additional keywords: horizontal gene transfer.

Pectin is a major structural component of the plant cell wall, along with cellulose and hemicellulose. Pectin is located mainly in the middle lamella and primary cell wall and functions as a matrix anchoring the cellulose and hemicellulose fibers (Carpita and Gibeaut 1993). The breakdown of pectin consequently leads to the maceration of plant tissues, the characteristic symptom of soft-rot diseases (Lietzke et al. 1994). Pectin degradation requires the combined action of several enzymes. These can be divided into two groups: pectin esterases, which remove the methoxyl groups from pectin, and depolymerases (hydrolases and lyases), which cleave the backbone chain (Tamaru and Doi 2001).

Pectate lyase (pectate transeliminase, EC 4.2.2.2), which catalyzes cleavage of internal $\alpha-1,4$-linkages of unesterified polygalacturonate (pectate) by $\beta$-elimination, is known to play a critical role in pectin degradation (Barras et al. 1994). Pectate lyases are classified as polysaccharide lyases and are present in 5 of 15 families $(1,2,3,9$, and 10) of this type of enzyme (Henrissat 1991; Henrissat and Davies 1997).

Corresponding author: Taisei Kikuchi; Telephone: 8129873 3211; Fax: 8129873 1543; E-mail: kikuchit@affrc.go.jp

Nucleotide and amino acid sequence data are available from the DDBJ database under accession numbers AB232906-AB232909 for Bx-pel-1/2 cDNA and genomic clones and AB232910-AB232912 for Bm-pel-1/2 cDNA and genomic clones.
Pectate lyases are widely distributed among bacterial and fungal plant pathogens and have been the focus of several studies that have aimed to ascertain their function as virulence factors (Barras et al. 1994). They are used by plant pathogens to degrade host cell walls in order to allow penetration and colonization. Plant-parasitic cyst nematodes and root-knot nematodes are known to secrete pectate lyases. Genes encoding pectate lyases have been cloned from several species of plant-parasitic nematodes, including Heterodera, Globodera (cyst nematode), and Meloidogyne (root-knot nematode) spp. (de Boer et al. 2002; Doyle and Lambert 2002; Huang et al. 2005; Popeijus et al. 2000). These pectate lyases are produced in the esophageal gland cells and are secreted from the stylet of the nematode. They are thought to play an important role in infection and parasitism of plants. Genes encoding other cellwall-degrading enzymes, including cellulase ( $\beta$-1,4-endoglucanase) (Gao et al. 2002; Rosso et al. 1999; Smant et al. 1998), polygaracturonase (Jaubert et al. 2002), and expansin (Qin et al. 2004), also have been identified in these nematodes. These enzymes also are secreted from the stylet of the nematodes; therefore, it has been suggested that these nematodes use a mixture of enzymes to attack the plant cell wall (Davis et al. 2004). These cell-wall-degrading enzymes are not found in other nematodes or almost any other animals, and are most similar to bacterial genes. This has led to the suggestion that they were acquired by horizontal gene transfer (HGT) from bacteria (Jones et al. 2005; Scholl et al. 2003).

The pine wood nematode, Bursaphelenchus xylophilus, is one of the most important plant-parasitic nematodes in Japan and East Asia. The nematode causes pine wilt disease and extensive mortality to pine trees, resulting in the annual loss of millions of pine trees in Japan (Mamiya 1983). B. xylophilus is not directly related to the plant-parasitic cyst and root-knot nematodes described above but is more closely related to fungal feeding nematodes with which it shares some life cycle characteristics.

Recently, we reported the cloning and functional characterization of cellulase $(\beta-1,4$-endoglucanase) genes from this nematode (Kikuchi et al. 2004). It was shown that the B. xylophilus cellulases are secreted thorough the stylet of this nematode and, like the cellulases of other plant-parasitic nematodes, may soften the plant cell wall to facilitate their feeding and migration. However, the B. xylophilus cellulases showed most similarity with fungal cellulases and were classified into glycosyl hydrolase family (GHF) 45, whereas cellulases of cyst or root-knot nematodes belong to GHF5 and are most similar to bacterial cellulases. Therefore, it was proposed that cyst or root-knot nematodes and Bursaphelenchus spp. might have evolved both the ability to digest cellulose and the ability to 
parasitize plants independently (Kikuchi et al. 2004). Here, we report the cloning and characterization of genes encoding a second category of plant cell-wall-degrading enzyme, pectate lyase, from B. xylophilus.

\section{RESULTS}

Identification of a pectate lyase gene from $B$. xylophilus.

Expressed sequence tags (ESTs) obtained from the $5^{\prime}$ end of genes present in a cDNA library constructed from mixed-stage B. xylophilus were searched using Blastn and Blastx programs for similar sequences in DNA and protein databases. A clone with significant similarity at the amino acid level with pectate lyases was identified and designated Bx-pel-1. The complete cDNA was $848 \mathrm{bp}$ in length and contained an open reading frame of 252 amino acids with an ATG start codon at position 12 and a TGA stop codon at position 768. The cDNA possesses a polyadenylation signal located $9 \mathrm{bp}$ upstream of the polyA tail. A signal peptide of 18 amino acids is predicted by the SignalP program (Nielsen et al. 1997) at the N-terminus of the deduced BxPEL1 polypeptide. The putative mature protein has a molecular mass of $25 \mathrm{kDa}$ and theoretical $\mathrm{pI}$ of 8.45. The deduced amino acid sequence of BxPEL1 showed highest similarity with pectate lyases belonging to polysaccharide lyase family 3 from bacteria, fungi, and nematodes. Subsequent EST analysis led to the identification of another cDNA from B. xylophilus that also could encode a protein (BxPEL2) similar to polysaccharide lyase family 3 pectate lyases and which also had a predicted signal peptide at the N-terminus. BXPEL1 and BXPEL2 share 64\% identity in amino acid sequences (Fig. 1). In addition, two cDNAs (Bm-pel-1 and Bmpel-2) that could encode similar proteins with predicted signal peptides were found in ESTs from a related but nonpathogenic nematode species, Bursaphelenchus mucronatus.

\section{Genomic analysis.}

Analysis of genomic DNA was performed to confirm the nematode origin of Bx-pel-1. A Southern blot containing genomic DNA from B. xylophilus and from the fungus on which the nematodes were reared, Botrytis cinerea, as a negative control, was made and hybridized with a DNA probe generated from the $B x$-pel- 1 cDNA. The probe hybridized specifically with DNA in both the EcoRI and HindIII digests of Bursaphelenchus xylophilus DNA (Fig. 2). No signal was obtained from Botrytis cinerea genomic DNA. The Bx-pel- 1 cDNA hybridized to multiple fragments and, because the genomic coding region does not contain EcoRI or HindIII sites, Bx-pel-1 could be a member of a small multigene family. In addition, the entire coding regions of the Bx-pel-1 or Bx-pel-2 gene were amplified from Bursaphelenchus xylophilus gDNA, and the polymerase chain reaction (PCR) products were cloned and sequenced. Analysis of these sequences showed that these were exactly the same as the cDNA sequences, except that one intron was present at the site indicated in Figure 1. The introns are bordered by canonical cissplicing sequences, and are AT rich (59.7\%). The intron positions of these genes were identical to each other (Fig. 1). The genomic coding region of Bm-pel-1 and Bm-pel-2 also were amplified by PCR. Sequence analysis of the PCR products showed that each of these genes has one intron at the same position as Bx-pel-1 and Bx-pel-2 (Fig. 1).

The intron position in the Bursaphelenchus genes (Bx-pel$1 / 2$ and Bm-pel-1/2) were compared with those of other nematode pectate lyase genes. Mi-pel-1 from Meloidogyne incognita has three introns in the coding region, one of which is at the same position as that in the Bursaphelenchus genes (Fig. 1). Gr-pel-1 from Globodera rostochiensis has six introns and Mi-pel-2 from M. incognita has two introns. Gr-pel-1 and $\mathrm{Mi}$ - pel-2 share two intron positions but none of the introns of these genes have the same position as that in the Bursaphelenchus genes and Mi-pel-1 (not shown).

\section{Spatial localization of Bx-Pel-1 mRNA.}

To determine which nematode cells express Bx-pel-1, in situ mRNA hybridization was performed. Digoxigenin-labeled antisense probes generated from $B x$-pel- 1 specifically hybridized with transcripts in the esophageal gland cells of $B$. xylophilus (Fig. 3A). No hybridization was observed in B. xylophilus with the control-sense cDNA probes of Bx-pel-1 (Fig. 3B). Hybridization signals were detected in female, male, and propagative larvae of $B$. xylophilus. We could not determine precisely which of the three gland cells of the nematode expressed $B x$ pel-1, because these cells overlap and are difficult to distinguish from each other (Nickle et al. 1981).

\section{Overexpression and purification of BXPEL1.}

The coding region of the Bx-pel-1 gene without the signal peptide was amplified by PCR and cloned into an expression vector. Induction of exponentially growing cultures of Escherichia coli transformants resulted in inclusion bodies containing most of the protein. However, solubilization in $8 \mathrm{M}$ urea followed by on-column renaturation yielded milligram amounts of soluble recombinant BxPEL1 (rBxPEL1) protein in high purity, as evidenced by electrophoretic homogeneity (Fig. 4).

\section{Enzyme properties.}

Zymograms of rBxPEL1 displayed a prominent polygalacturonic acid (PGA)-degrading activity band at approximately $27 \mathrm{kDa}$ (Fig. 5). Similar analysis of nematode homogenate demonstrated an activity band at $25 \mathrm{kDa}$ (Fig. 5). These sizes are in agreement with the molecular mass predicted from the amino acid sequences of these proteins.

Of the pectic substrates tested, maximum activity was found on PGA (Fig. 6A). Moreover, as the percentage degree of methylation in pectin became higher, the activity of rBxPEL1 was reduced.

The effect of $\mathrm{pH}$ and temperature on the activity of purified rBxPEL1 on PGA were determined. The optimal temperature for $\mathrm{rBxPEL} 1$ activity was $55^{\circ} \mathrm{C}$, and greater than $50 \%$ of maximum activity was found in the temperature range from 50 to $65^{\circ} \mathrm{C}$ (Fig. 6C). rBxPEL1 was active on PGA in a broad alkaline $\mathrm{pH}$ range. Activity increased moderately with an increasing $\mathrm{pH}$ until 10.0, after which it decreased rapidly (Fig. 6D).

$\mathrm{Ca}^{2+}$ is known to be essential for the catalytic activity of pectate lyases; therefore, the influence of $\mathrm{Ca}^{2+}$ ions on enzymatic activity was examined using different $\mathrm{CaCl}_{2}$ concentrations (Fig. $6 \mathrm{~B})$. Activity was undetectable without this ion. Maximum activity was observed at 0.25 to $0.5 \mathrm{mM} \mathrm{CaCl}_{2}$ and activity decreased at higher concentrations. The addition of $1 \mathrm{mM}$ EDTA to the standard mixture completely eliminated pectate lyase activity (data not shown). The effect of metal ions other than $\mathrm{Ca}^{2+}$ on pectate lyase activity was determined by performing enzyme assays on PGA in the presence of metal ions at $1 \mathrm{mM}$ concentration. $\mathrm{Ca}^{2+}$ was not present in these assays. When $\mathrm{rBxPEL1}$ was evaluated in the presence of $\mathrm{Mg}^{2+}, \mathrm{Mn}^{2+}, \mathrm{Co}^{2+}, \mathrm{Ni}^{2+}, \mathrm{Zn}^{2+}$, and $\mathrm{Ba}^{2+}$, no pectate lyase activity was detected (data not shown), indicating that none of the ions tested could replace $\mathrm{Ca}^{2+}$.

\section{Phylogenetic analysis.}

A phylogenetic tree was generated from an alignment of Bursaphelenchus sequences with selected proteins belonging to polysaccharide lyase family 3 from bacteria, fungi, and nematodes using the maximum likelihood method. Analysis using a neighbor-joining method generated trees with similar topology. Bx-pel-1 and 2 from B. xylophilus and Bm-pel-1 and 
2 from B. mucronatus were clustered together with strong bootstrap support (Fig. 7). However, other nematode sequences were not monophyletic but were clustered into three distinct clades (Fig. 7). In addition, no clear relationship between nematode sequences and either bacterial or fungal sequences emerged from the tree.

\section{DISCUSSION}

In this article, we describe pectate lyases from the pine wood nematode B. xylophilus. This is the first identification of a pectate lyase from a plant-parasitic nematode belonging to the order Aphelenchida.

The observation that the $B x$-pel- 1 probe specifically hybridized to nematode DNA in Southern blot analysis, the presence of a poly-A tail at the $3^{\prime}$ end of the cDNA, and the presence of introns within the coding region amplified from genomic DNA support a nematode origin for Bx-pel-1. In addition, in situ hybridization showed that the gene is expressed solely in the esophageal gland cells of $B$. xylophilus, a tissue from which no endosymbiotic bacteria have ever been described. These lines of evidence demonstrate that the pectate lyase genes are endoge-
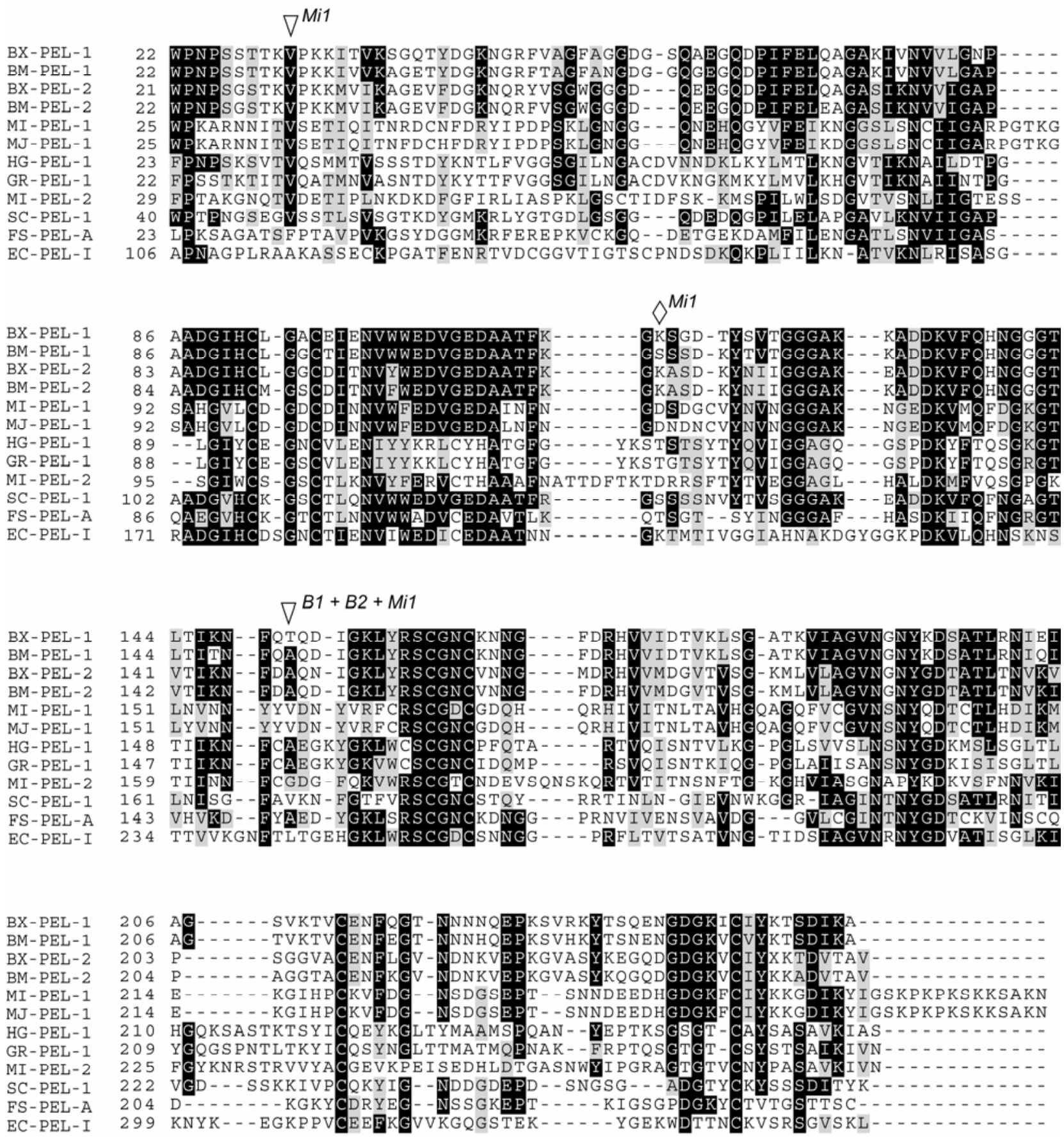

Fig. 1. Multiple sequence alignment of pectate lyases belonging to polysaccharide lyase family 3. BX-PEL-1, BX-PEL-2, BM-PEL-1, and BM-PEL-2 from this study; MI-PEL-1 (AAQ09004) and MI-PEL-2 (AAQ97032) from Meloidogyne incognita; MJ-PEL-1 (AAL66022) from M. javanica; HG-PEL-1 (AAK08974) from Heterodera glycines; GR-PEL-1 (AAF80747) from Globodera rostochiensis; SC-PEL-1 (CAC13062) from Streptomyces coelicolor; FSPEL-A (AAA33338) from Fusarium solani; and EC-PEL-I (CAA73784) from Erwinia chrysanthemi. Identical residues are highlighted in black and functionally conserved are in gray. The positions of the intron in BxPEL1 and BmPEL1 is indicated by B1, that in BxPEL2 and BmPEL2 by B2, and those in MI-ENG-1 by Mil. Triangles and diamonds represent phase 0 and 1 introns, respectively. 
nous nematode genes and were not derived from bacterial contaminants or symbionts or from the fungi on which the nematodes were reared.

The presence of a signal peptide in the deduced amino acid sequence of Bx-pel-1 and its expression in the esophageal glands suggest that BxPEL1 is secreted from the stylet of the nematode. B. xylophilus is required to migrate within plant tissue during its lifecycle. Once the nematode invades the pine tree, it migrates primarily through resin canals of the tree and feeds from parenchyma cells surrounding the canals (Mamiya 1983). Although pectin substrates are scarce in the xylem of woody plants, they are present in the primary cell wall of the cambium and parenchyma cells of woody plants, including pine trees (Hafren et al. 2000; Westermark et al. 1986). Therefore, it is likely that BxPEL1 is secreted from the nematode stylet and helps the nematode migrate and feed within the tree. In a previous study, we showed that the nematode secretes cellulase (Kikuchi et al. 2004). In addition, we also showed that the nematode secretes endo- $\beta$-1,3-glucanase which degrades $\beta$-1,3-glucan, a major component of the fungal cell wall

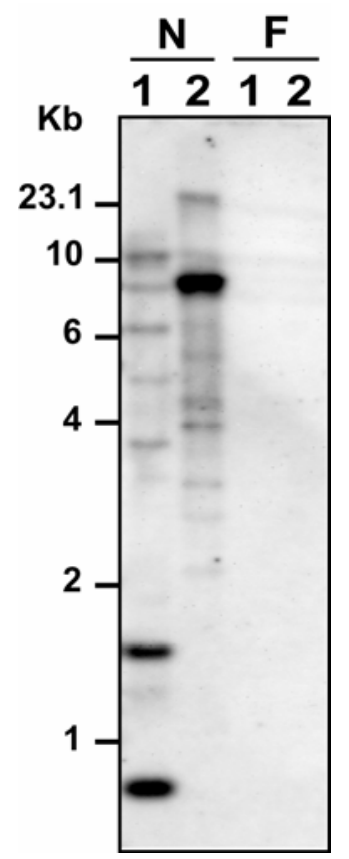

Fig. 2. Genomic Southern analysis of Bx-pel-1. A blot containing genomic DNA from nematode Bursaphelenchus xylophilus $(\mathrm{N})$ and fungus Botrytis cinerea (F) digested with EcoRI (1) and HindIII (2) was hybridized with a Bx-pel-1-specific probe. The probe hybridizes to a series of bands in the nematode DNA indicating the presence of a multigene family.
(Kikuchi et al. 2005). Therefore, B. xylophilus secretes a mixture of enzymes to attack both the plant and fungal cell walls.

Recombinant BxPEL1 was produced as inclusion bodies in $E$. coli but could be recovered by a single-step purification and renaturation procedure. Renatured protein showed the highest activity on PGA. The amino acid sequence of BxPEL1 shows high similarity with those of proteins belonging to polysaccharide lyase family 3 , and the biochemical properties of $\mathrm{rBxPEL} 1$ also were similar to those of other polysaccharide lyase family 3 pectate lyases. For example, BxPEL1 has a rather high optimal temperature $\left(55^{\circ} \mathrm{C}\right)$, retains activity over a broad alkaline $\mathrm{pH}$ range, and showed an absolute requirement for $\mathrm{Ca}^{2+}$ ion for activity. BxPEL1 seems to be particularly active at temperatures that are much higher than those found in the normal environmental conditions that the nematodes would encounter. This also is the case for several nonthermophilic bacterial pectate lyases (Soriano et al. 2000; Tardy et al. 1997). Furthermore, nematode homogenate showed the highest pectate lyase activity on PGA at a temperature similar to recombinant BxPEL1 (data not shown), indicating that this high optimum enzymatic temperature is not likely to be a result of bacterial expression or the subsequent denaturation and renaturation of the enzyme.

Polysaccharide lyase family 3 pectate lyases have been found from plant-parasitic cyst and root-knot nematodes, including $M$. incognita, M. javanica, Heterodera glycines, and

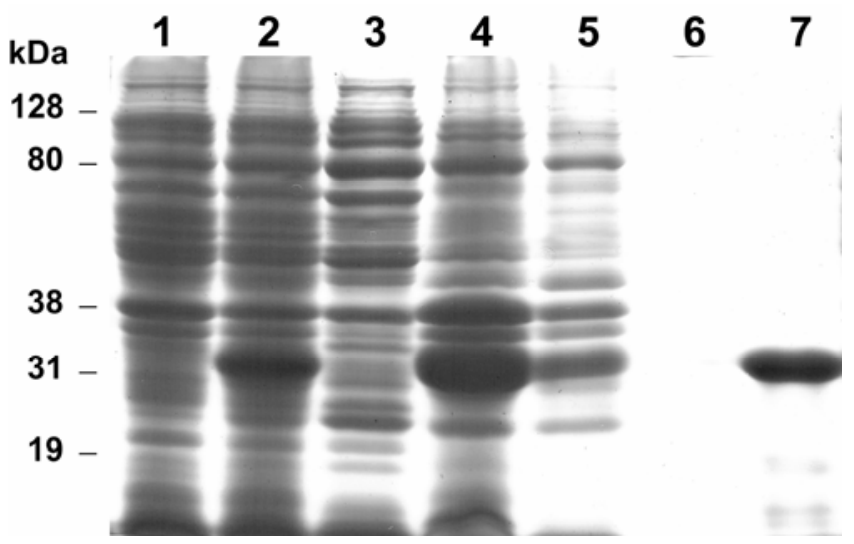

Fig. 4. Sodium dodecyl sulfate-polyacrylamide gel electrophoresis profile of expression, purification, and refolding of recombinant BxPEL1. Lanes 1 and 2, crude extract from cells before (lane 1) and after (lane 2) induction with isopropyl- $\beta$-D-thiogalactopyranoside; lane 3 and $4,10,000 \times g$ supernatant (lane 3) and pellet (lane 4) fractions derived from cell lysate expressing BxPEL1; lane 5, flow-through from HisTrap HP column after solubilization with $8 \mathrm{M}$ urea; lane 6 , first wash-through; lane 7, proteins recovered after elution from the HisTrap HP column with imidazole buffer without urea.
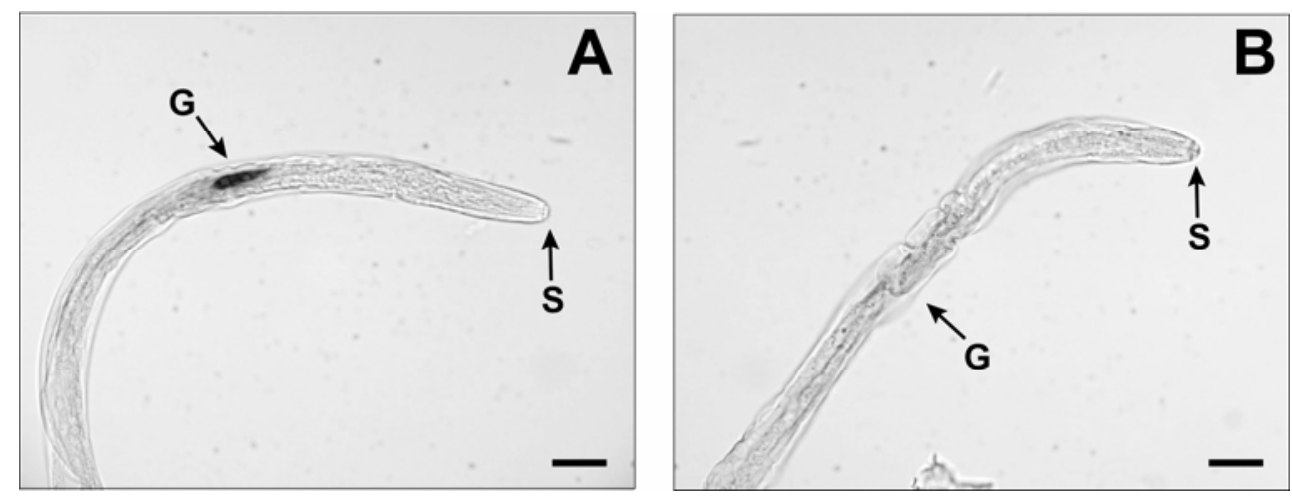

Fig. 3. Localization by in situ hybridization of the Bx-pel-1 transcripts. Nematode sections were hybridized with A, antisense or B, sense Bx-pel-1 digoxigeninlabeled cDNA probe. G: esophageal glands and S: stylet. Scale bar $=10 \mu \mathrm{m}$. 
G. rostochiensis, all belonging to the order Tylenchida (de Boer et al. 2002; Doyle and Lambert 2002; Huang et al. 2005; Popeijus et al. 2000). They are likely to play important roles in infection and parasitism. The pectate lyases described here come from nematodes belonging to the order Aphelenchida,

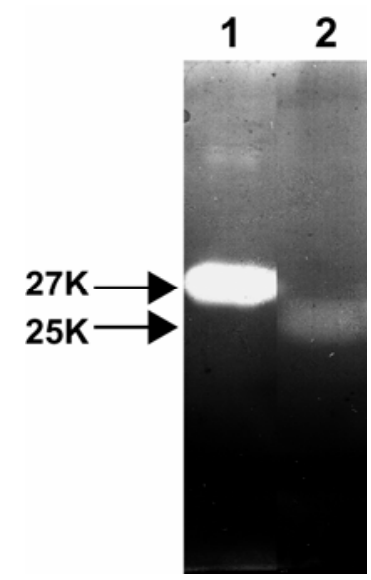

Fig. 5. Zymography showing the pectate lyase activity of the recombinant BxPEL1 (lane 1) and nematode homogenate (lane 2) in a sodium dodecyl sulfate-polyacrylamide gel containing polygalacturonic acid. indicating that pectate lyases are common in plant-parasitic nematodes. Phylogenetic analysis of the pectate lyases, including those from bacteria, fungi, and nematodes, resulted in a tree in which the nematode sequences were not monophyletic. The sequences from B. xylophilus and B. mucronatus were clustered in the same clade but were not most closely related with sequences from cyst and root-knot nematodes. Furthermore, sequences from cyst and root-knot nematodes were clustered in two separate groups. This is perhaps because multiple paralogous genes are present in the various nematode genomes. This analysis also was difficult due to the relatively high levels of similarity between the nematode genes and pectate lyases from both bacteria and fungi. Blast searching revealed that the cyst and root-knot nematode and Bursaphelenchus pectate lyase genes are most similar to genes from bacteria, and the genes from all nematode species are most similar to pectate lyases from the same bacterial species. Although it is difficult to determine conclusively from this analysis whether the nematode pectate lyase genes have an ancient, common origin, it seems likely that this was the case and that the genes were acquired by a common ancestor in a single HGT event. Further support for this idea comes from the observation that the position of the intron in one pectate lyase gene from $M$. incognita (Mi-Pel-1) and the Bursaphelenchus genes is conserved. However, recently acquired introns in nematodes have a preference
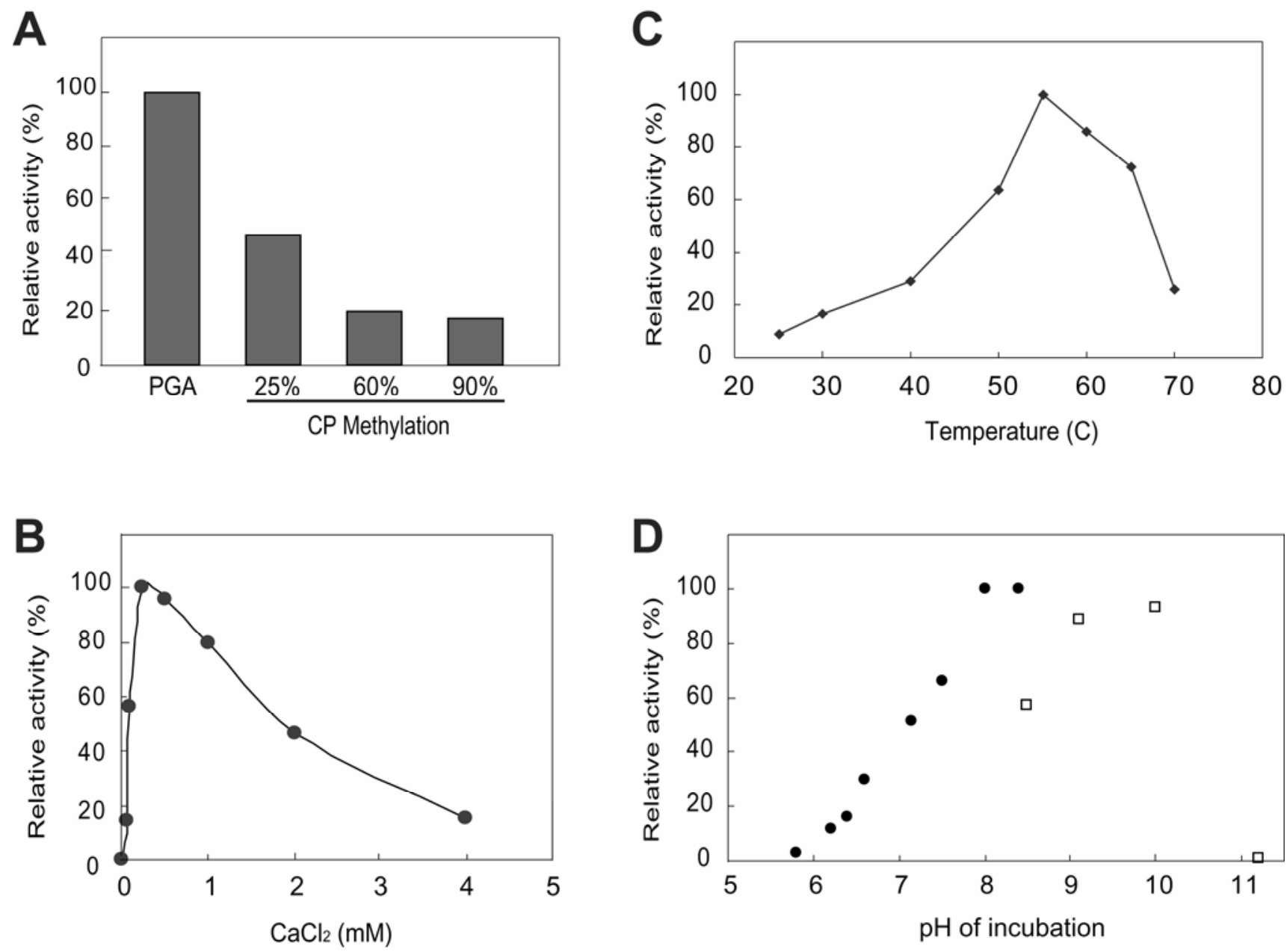

Fig. 6. Biochemical characterization of purified recombinant BxPEL1. A, Effect of the degree of pectin methylation on rBxPEL1 activity. Activity of rBxPEL1 on polygalacturonic acid (PGA) and citrus pectin (CP) with a degree of methyl esterification from 25 to $90 \%$ was determined in the standard assay mixture. B, Effect of $\mathrm{Ca}^{2+}$ concentration on rBxPEL1 activity on PGA. C, rBxPEL1 activity on PGA as a function of temperature. Activity was measured at the indicated temperatures in the standard assay mixture. D, rBxPEL1 activity on PGA as a function of $\mathrm{pH}$. $\mathrm{rBxPEL} 1$ activity was measured in $50 \mathrm{mM}$ Tris-HCl buffer (pH range, 5.8 to 8.3 ) (O) or $50 \mathrm{mM}$ glycine- $\mathrm{NaOH}$ buffer (pH range, 8.5 to 11.3) ( $\square$ ). The $\mathrm{pH}$ values are those measured in the final reaction mixture. 
for insertion at specific sequence sites (Coghlan and Wolfe 2004). Therefore, in genes acquired by HGT from bacteria, it is possible that the positions at which introns can be inserted are limited, thus artificially biasing any analysis using intron position as an indicator of common evolutionary origin.

This work shows that pectate lyases are present in both $B$. xylophilus and B. mucronatus. B. mucronatus is very closely related to $B$. xylophilus and the two species share many characteristics in their life cycles. However, B. mucronatus is not pathogenic to plants and lives only in dead or dying pine trees where it feeds on colonizing fungi. This suggests that pectate lyases are used for migration through both living and dead plant tissues. Therefore, it is possible that cell-wall-degrading enzymes might be more widely used by nematodes in plantnematode associations than previously was thought.

\section{MATERIALS AND METHODS}

\section{Biological material.}

B. xylophilus isolate Ka-4 was used in this study, which subsequently was cultured on Botrytis cinerea grown on autoclaved barley grains for 1 week at $25^{\circ} \mathrm{C}$ before being subcultured or harvested for experiments. Nematodes for experiments were separated from Botrytis cinerea hyphae as described previously (Kikuchi et al. 2004).

\section{Isolation of cDNA and gDNA clone.}

The pectate lyase gene was cloned as a part of an EST project carried out using a cDNA library derived from mixedstage Bursaphelenchus xylophilus (T. Kikuchi, unpublished results). One full-length cDNA (clone 03EK1-03-E09) encoding a pectate lyase, designated $B x$-pel-1, was identified during BLAST analyses of sequences generated in this project. A further cDNA clone encoding a related but different sequence (Bx-pel-2) also was identified in the ESTs. The plasmid clones from which each of these sequences were obtained were identified and resequenced in both directions in order to obtain full-length cDNA sequences. Similar methods were use to identify pectate lyase encoding cDNAs from ESTs of a related species, B. mucronatus.

The genomic coding region of each cDNA clone was obtained by PCR amplification from B. xylophilus genomic DNA, using pairs of gene-specific primers flanking each open reading frame. PCR products were cloned using the pGEM-T Easy vector (Promega Corp., Madison, WI, U.S.A.) and sequenced.

\section{Southern blot analysis.}

Genomic DNA was prepared from nematodes or Botrytis cinerea as described previously (Kikuchi et al. 2004). DNA gel blot analysis using the hybridization membrane Hybond $\mathrm{N}$ (Amersham Bioscience, Piscataway, NJ, U.S.A.) was performed using standard protocols (Sambrook and Russell 2001). A probe specific to Bx-pel-1 was made by PCR amplification of the fulllength cDNA from the original plasmid with primers pel00s $\left(5^{\prime}\right.$ GTCCGTTGAAGATGGTCCAA 3') and pel00a (5' CAGATAA TTAGGTTCAGAACG $3^{\prime}$ ). The PCR product was gel purified using a MinElute gel extraction kit (Qiagen, Tokyo). Labeling of probes with digoxigenin and detection of signal were performed according to the instructions of the manufacturer (Roche Diagnostics, Mannheim, Germany). CDPstar (Roche Diagnostics) was used as a substrate for alkaline phosphatase.

\section{Expression and purification of recombinant protein.}

The coding region of BxPEL1 without the putative signal sequence was amplified by PCR and then cloned into the bacterial expression vector pQE-30UA (Qiagen). The $6 \times$ Histagged protein was expressed in E. coli M15[pREP4] (Qiagen). After inducing protein expression for $6 \mathrm{~h}$ at $37^{\circ} \mathrm{C}$ with $1 \mathrm{mM}$ isopropyl- $\beta$-D-thiogalactopyranoside, bacteria were harvested by centrifugation. The protein was purified from inclusion

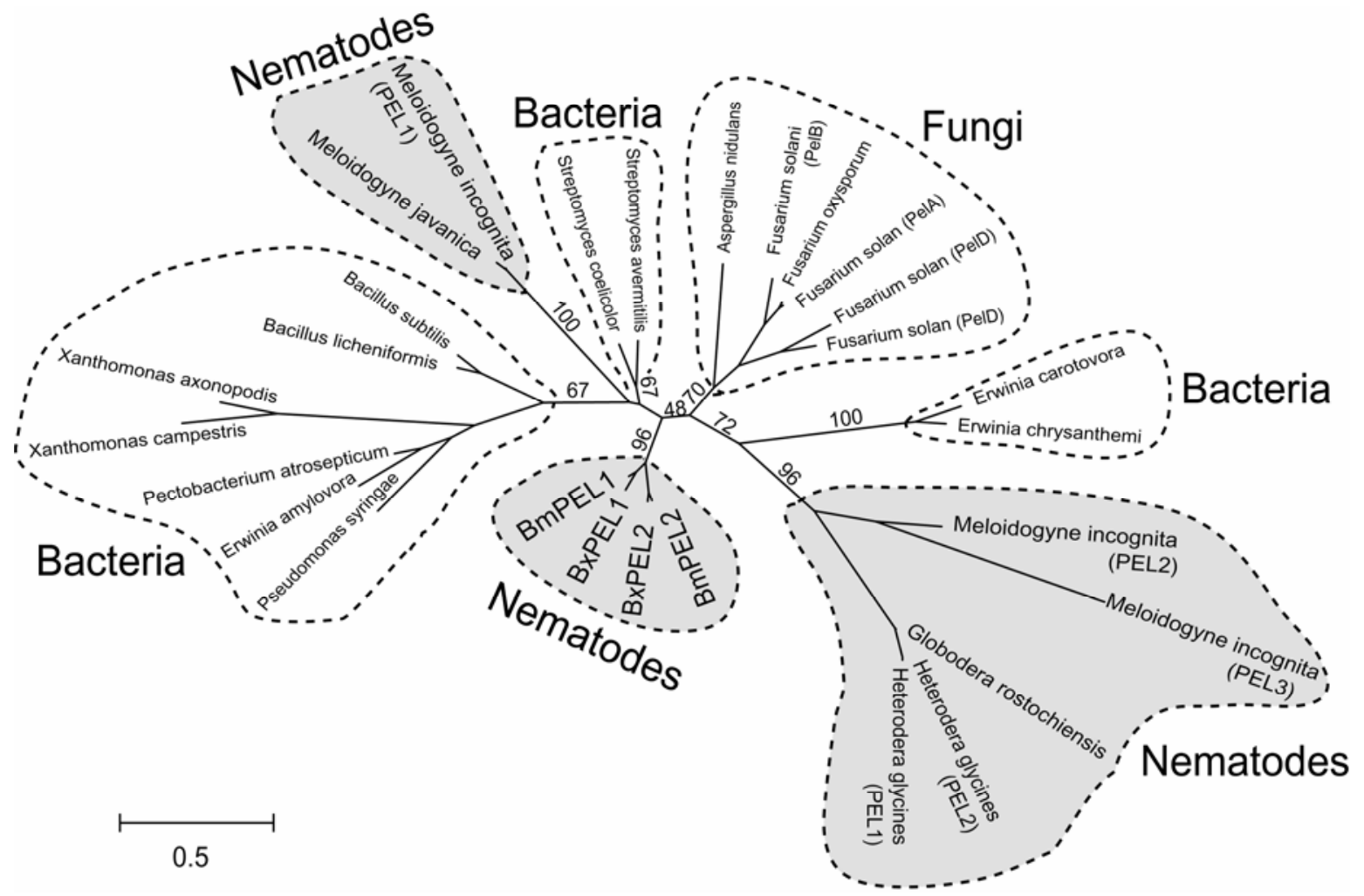

Fig. 7. Unrooted phylogenetic tree of selected polysaccharide lyase family 3 proteins generated using maximum likelihood analysis. The numbers on the node represent the bootstrap support percentages. The scale bar represents 50 substitutions per 100 amino acid positions. 
bodies using HisTrap HP Column (Amersham Biosciences) after being solubilized with $8 \mathrm{M}$ urea. To recover the activity of the recombinant BxPEL1 (rBxPEL1), the protein was renatured on the column before elution with $0.5 \mathrm{M}$ imidazole as described (Holzinger et al. 1996). The purity of the protein was assessed by sodium dodecyl sulfate-polyacrylamide gel electrophoresis (SDS-PAGE).

\section{SDS-PAGE and zymography.}

Protein samples were boiled in an equal volume of $2 \times$ sample buffer (100 mM Tris, pH 6.8, 12\% 2-mercaptoethanol, 4\% SDS, $20 \%$ glycerol, and $0.01 \%$ bromphenol blue) for $3 \mathrm{~min}$ and analyzed by SDS-PAGE in $12 \%$ polyacrylamide gel (Laemmli 1970). After electrophoresis, the gel was stained with Coomassie brilliant blue. For zymogram staining, samples were boiled for $3 \mathrm{~min}$ in $2 \times$ sample buffer without 2-mercaptoethanol before loading on a $12 \%$ SDS-PAGE gel containing $0.05 \%$ (wt/vol) PGA. Proteins were renatured by soaking the gel successively once in potassium phosphate buffer $(50 \mathrm{mM}$, $\mathrm{pH} 7.0$ ) containing 2-propanol (25\%, vol/vol) for $30 \mathrm{~min}$, and twice in potassium phosphate buffer. After incubation at $37^{\circ} \mathrm{C}$ for $16 \mathrm{~h}$, gels were stained with $0.05 \%$ (wt/vol) Ruthenium red (Nacalai Tesque, Kyoto, Japan) for $10 \mathrm{~min}$ and washed with water until pectate lyase bands became visible.

Nematode homogenate for zymography analysis was prepared as described previously (Kikuchi et al. 2004).

\section{Enzyme assays.}

Pectate lyase activity was assayed spectrophotometrically by measuring the formation of unsaturated products from PGA at $232 \mathrm{~nm}$ (Collmer et al. 1988). The standard assay mixture contained $100 \mu \mathrm{l}$ of $3 \%$ polygalacturonic acid (Sigma-Aldrich, St. Louis), $500 \mu \mathrm{l}$ of $0.1 \mathrm{M}$ Tris- $\mathrm{HCl}$ (pH 8.0), $100 \mu \mathrm{l}$ of $10 \mathrm{mM}$ $\mathrm{CaCl}_{2}$, and $10 \mu \mathrm{l}$ of appropriately diluted enzyme solution in a total volume of $1 \mathrm{ml}$. The subsequent increase in absorbance at $232 \mathrm{~nm}$ was monitored at $25^{\circ} \mathrm{C}$ over a period of $5 \mathrm{~min}$. The $\mathrm{pH}$ values of these buffers were confirmed at room temperature.

The activity of recombinant protein on substrates with various degrees of methylation was determined by substituting 26, 67 , and $89 \%$ esterified citrus fruit pectins (Sigma-Aldrich) or polygalacturonic acid (Sigma-Aldrich). The influence of $\mathrm{Ca}^{2+}$ was investigated by the addition of $\mathrm{CaCl}_{2}$ to final concentrations ranging from 0 to $4 \mathrm{mM}$. The optimum $\mathrm{pH}$ was determined by using Tris-HCl buffer ( $\mathrm{pH} 5.8$ to 8.5) and glycine$\mathrm{NaOH}$ buffer (pH 8.5 to 11 ), each at $50 \mathrm{mM}$. The $\mathrm{pH}$ values were determined in the final reaction mixture.

\section{In situ hybridization.}

The spatial localization of the mRNA was examined by using in situ hybridization performed essentially as described by de Boer and associates (1998). In short, PCR products were generated with the primers pel00s and pel00a and sense or antisense strand was labeled with digoxigenin (Roche Diagnostics). These probes were hybridized to fragments of mixedstage Bursaphelenchus xylophilus that previously had been fixed with $4 \%$ paraformaldehyde and permeabilized with proteinase K. After washing, bound probes were detected using an anti-digoxigenin antibody conjugated to alkaline phosphatase (Roche Diagnostics), which was revealed with nitroblue tetrazolium and bromo-chloro-indolyl phosphate. Specimens were examined with differential interference contrast microscopy.

\section{Phylogenetic analysis.}

Protein sequences which belong to polysaccharide lyase family 3 from bacteria, fungi, and nematodes were obtained from the CAZy database and aligned with the new sequences (BxPEL1,2 and BmPEL1,2) using the ClustalX 1.8 program
(Thompson et al. 1997) followed by manual refinement. Prior to phylogenetic analysis, signal peptide sequences and other $\mathrm{N}$ - and C-terminal extensions peculiar to individual taxa were excluded. In total, 129 characters were used for phylogenetic analysis. Neighbor-joining trees were constructed in MEGA v 3.1 (Kumar et al. 2004), using the JTT amino acid substitution matrix. Maximum likelihood analyses were carried out with Phyml v 2.4 (Guindon and Gascuel 2003) using the JTT amino acid substitution matrix. Support for the resulting neighborjoining and maximum likelihood trees was assessed by bootstrap resampling.

\section{ACKNOWLEDGMENTS}

This work was funded by research grant \#200302 of the Forrestry and Forest Products Research Institute and by Scottish Executive Environmente and Royal Affairs Department project number SCR/615/04 (J. T. Jones).

\section{LITERATURE CITED}

Barras, F., Gijsegem, F. V., and Chatterjee, A. K. 1994. Extracellular enzymes and pathogenesis of soft-rot Erwinia. Annu. Rev. Phytopathol. 32:201-234.

Carpita, N. C., and Gibeaut, D. M. 1993. Structural models of primary cell walls in flowering plants: consistency of molecular structure with the physical properties of the walls during growth. Plant J. 3:1-30.

Coghlan, A., and Wolfe, K. H. 2004. Origins of recently gained introns in Caenorhabditis. Proc. Natl. Acad. Sci. U.S.A. 101:11362-11367.

Collmer, A., Ried, J. L., and Mount, M. S. 1988. Assay methods for pectic enzymes. Methods Enzymol. 161:329-335.

Davis, E. L., Hussey, R. S., and Baum, T. J. 2004. Getting to the roots of parasitism by nematodes. Trends Parasitol. 20:134-141.

de Boer, J. M., Yan, Y., Smant, G., Davis, E. L., and Baum, T. J. 1998. Insitu hybridization to messenger RNA in Heterodera glycines. J. Nematol. 30:309-312.

de Boer, J. M., McDermott, J. P., Davis, E. L., Hussey, R. S., Popeijus, H., Smant, G., and Baum, T. J. 2002. Cloning of a putative pectate lyase gene expressed in the subventral esophageal glands of Heterodera glycines. J. Nematol. 34:9-11.

Doyle, E. A., and Lambert, K. N. 2002. Cloning and characterization of an esophageal-gland-specific pectate lyase from the root-knot nematode Meloidogyne javanica. Mol. Plant-Microbe Interact. 15:549-556.

Gao, B., Allen, R., Maier, T., Davis, E. L., Baum, T. J., and Hussey, R. S. 2002. Identification of a new $\beta$-1,4-endoglucanase gene expressed in the esophageal subventral gland cells of Heterodera glycines. J. Nematol. $34: 12-15$.

Guindon, S., and Gascuel, O. 2003. A simple, fast, and accurate algorithm to estimate large phylogenies by maximum likelihood. Syst. Biol. 52:696-704.

Hafren, J., Daniel, G., and Westermark, U. 2000. The distribution of acidic and esterified pectin in cambium, developing xylem and mature xylem of Pinus sylvestris. Iawa J. 21:157-168.

Henrissat, B. 1991. A classification of glycosyl hydrolases based on amino acid sequence similarities. Biochem. J. 280(Part 2):309-316.

Henrissat, B., and Davies, G. 1997. Structural and sequence-based classification of glycoside hydrolases. Curr. Opin. Struct. Biol. 7:637-644.

Holzinger, A., Phillips, K. S., and Weaver, T. E. 1996. Single-step purification/solubilization of recombinant proteins: application to surfactant protein B. BioTechniques 20:804-806, 808.

Huang, G., Dong, R., Allen, R., Davis, E. L., Baum, T. J., and Hussey, R. S. 2005. Developmental expression and molecular analysis of two Meloidogyne incognita pectate lyase genes. Int. J. Parasitol. 35:685-692.

Jaubert, S., Laffaire, J. B., Abad, P., and Rosso, M. N. 2002. A polygalacturonase of animal origin isolated from the root-knot nematode Meloidogyne incognita. FEBS (Fed. Eur. Biol. Soc.) Lett. 522:109-112.

Jones, J. T., Furlanetto, C., and Kikuchi, T. 2005. Horizontal gene transfer from bacteria and fungi as a driving force in the evolution of plant parasitism in nematodes. Nematology 17:641-646.

Kikuchi, T., Jones, J. T., Aikawa, T., Kosaka, H., and Ogura, N. 2004. A family of glycosyl hydrolase family 45 cellulases from the pine wood nematode Bursaphelenchus xylophilus. FEBS (Fed. Eur. Biol. Soc.) Lett. 572:201-205.

Kikuchi, T., Shibuya, H., and Jones, J. T. 2005. Molecular and biochemical characterization of an endo- $\beta$-1,3-glucanase from the pinewood nematode Bursaphelenchus xylophilus acquired by horizontal gene transfer from bacteria. Biochem. J. 389:117-125. 
Kumar, S., Tamura, K., and Nei, M. 2004. MEGA3: integrated software for molecular evolutionary genetics analysis and sequence alignment. Brief. Bioinform. 5:150-163.

Laemmli, U. K. 1970. Cleavage of structural proteins during the assembly of the head of bacteriophage T4. Nature 227:680-685.

Lietzke, S. E., Yoder, M. D., Keen, N. T., and Jurnak, F. 1994. The threedimensional structure of pectate lyase E, a plant virulence factor from Erwinia chrysanthemi. Plant Physiol. 106:849-862.

Mamiya, Y. 1983. Pathology of the pine wilt disease caused by Bursaphelenchus xylophilus. Annu. Rev. Phytopathol. 21:201-220.

Nickle, W. R., Golden, A. M., Mamiya, Y., and Wergin, W. P. 1981. On the taxonomy and morphology of the pine wood nematode, Bursaphelenchus xylophilus (Steiner \& Buhrer 1934) Nickle 1970. J. Nematol. 13:385-392.

Nielsen, H., Engelbrecht, J., Brunak, S., and vonHeijne, G. 1997. Identification of prokaryotic and eukaryotic signal peptides and prediction of their cleavage sites. Protein Eng. 10:1-6.

Popeijus, H., Overmars, H., Jones, J., Blok, V., Goverse, A., Helder, J., Schots, A., Bakker, J., and Smant, G. 2000. Degradation of plant cell walls by a nematode. Nature 406:36-37.

Qin, L., Kudla, U., Roze, E. H., Goverse, A., Popeijus, H., Nieuwland, J., Overmars, H., Jones, J. T., Schots, A., Smant, G., Bakker, J., and Helder, J. 2004. Plant degradation: a nematode expansin acting on plants. Nature 427:30.

Rosso, M. N., Favery, B., Piotte, C., Arthaud, L., de Boer, J. M., Hussey, R. S., Bakker, J., Baum, T. J., and Abad, P. 1999. Isolation of a cDNA encoding a $\beta$-1,4-endoglucanase in the root-knot nematode Meloidogyne incognita and expression analysis during plant parasitism. Mol. Plant-Microbe Interact. 12:585-591.

Sambrook, J., and Russell, D. W. 2001. Molecular Cloning: A Laboratory Manual. Cold Spring Harbor Laboratory Press, Cold Spring Harbor, NY, U.S.A.
Scholl, E. H., Thorne, J. L., McCarter, J. P., and Bird, D. M. 2003. Horizontally transferred genes in plant-parasitic nematodes: a high-throughput genomic approach. Genome Biol. 4:R39.

Smant, G., Stokkermans, J. P., Yan, Y., de Boer, J. M., Baum, T. J., Wang, X., Hussey, R. S., Gommers, F. J., Henrissat, B., Davis, E. L., Helder, J., Schots, A., and Bakker, J. 1998. Endogenous cellulases in animals: isolation of $\beta$-1,4-endoglucanase genes from two species of plant-parasitic cyst nematodes. Proc. Natl. Acad. Sci. U.S.A. 95:4906-4911.

Soriano, M., Blanco, A., Diaz, P., and Pastor, F. I. 2000. An unusual pectate lyase from a Bacillus sp. with high activity on pectin: cloning and characterization. Microbiology 146(Part 1):89-95.

Tamaru, Y., and Doi, R. H. 2001. Pectate lyase A, an enzymatic subunit of the Clostridium cellulovorans cellulosome. Proc. Natl. Acad. Sci. U.S.A. 98:4125-4129.

Tardy, F., Nasser, W., Robert-Baudouy, J., and Hugouvieux-Cotte-Pattat, N. 1997. Comparative analysis of the five major Erwinia chrysanthemi pectate lyases: enzyme characteristics and potential inhibitors. J. Bacteriol. 179:2503-2511.

Thompson, J. D., Gibson, T. J., Plewniak, F., Jeanmougin, F., and Higgins, D. G. 1997. The CLUSTAL X windows interface: flexible strategies for multiple sequence alignment aided by quality analysis tools. $\mathrm{Nu}$ cleic Acids Res. 25:4876-4882.

Westermark, U., Hardell, H. L., and Iversen, T. 1986. The content of protein and pectin in the lignified middle lamella primary wall from spruce fibers. Holzforschung 40:65-68.

\section{AUTHOR-RECOMMENDED INTERNET RESOURCE}

CAZy-Carbohydrate active enzymes website: afmb.cnrsmrs.fr/CAZY/index.html 